\title{
An International Professional Development Collaboration: Supporting Teachers in the Kingdom of Saudi Arabia through an Immer- sion Program in the United States
}

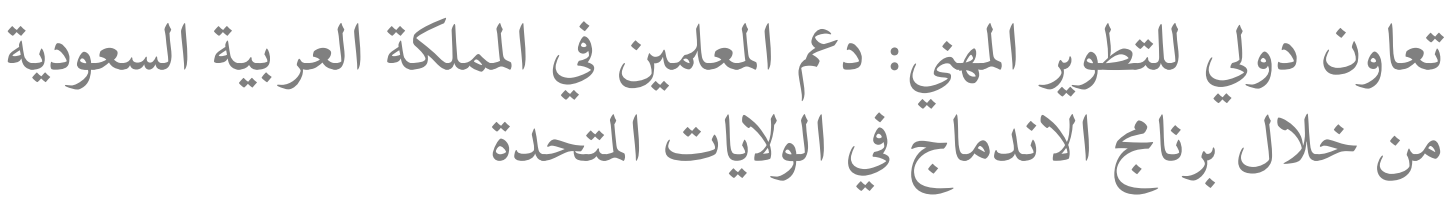

Corresponding Author:

Amrein-Beardsley;

email:

audrey.beardsley@asu.edu

Submitted: February 25, 2021

Accepted: September 1, 2021

Published: January 31, 2022

Production and Hosting by Knowledge E

(c) Byoung-gyu Gong et

al.. This article is distributed under the terms of the

Creative Commons

Attribution License, which

permits unrestricted use and redistribution provided that the original author and source are credited.

Managing Editor:

Natasha Mansu Utah, United States

\section{Byoung-gyu Gong ${ }^{1}$, Clarin Collins ${ }^{2}$, Audrey Amrein-Beardsley ${ }^{2}$}

${ }^{1}$ Sorenson Impact Center, David Eccles School of Business, University of Utah, Salt Lake City,

${ }^{2}$ Mary Lou Fulton Teachers College, Arizona State University, Tempe, Arizona, United States

\section{ORCID}

Byoung-gyu Gong: https://orcid.org/0000-0002-7537-7502

Clarin Collins: https://orcid.org/0000-0003-1630-9881

Audrey Amrein-Beardsley: https://orcid.org/0000-0001-6924-3025

\section{Abstract}

The Kingdom of Saudi Arabia (KSA) recently initiated multiple, one-year, school immersion programs to help 25,000 KSA teachers better support KSA students and the KSA education system after spending time abroad in teacher education programs throughout the United States (US). This study explored the effects of one such program, aimed at helping KSA teachers become agents of change. The authors examined how the $46 \mathrm{KSA}$ teachers involved in this program changed. Survey-research and English language tests were used to show that the immersion program yielded its desired effects: the program increased teachers' sense of efficacy; improved teachers' pedagogical, content, technical, and English language skills; and enhanced teachers' understandings of education across nations and cultures, with emphasis on the transfer of features of the US educational system back to the KSA (although teachers were uncertain about the extent to which the transference desired might actually occur). Via supplemental interviews, the authors also identified self-reported influential sources of change. The article examines how these sources of change impacted KSA teachers' mindsets regarding their teaching. The study confirms that the program influenced participants through their school immersion experiences, given that the program offered KSA teachers chances to learn more about student-centered learning approaches and more customized and individualized care for students.

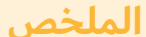

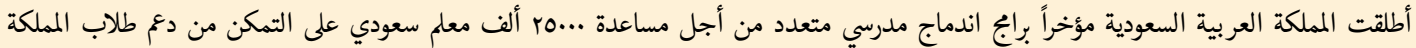

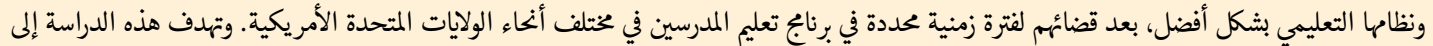

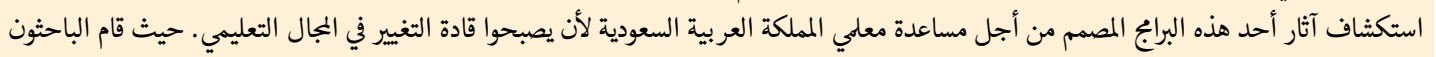

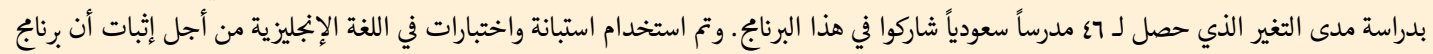

\section{G OPEN ACCESS}




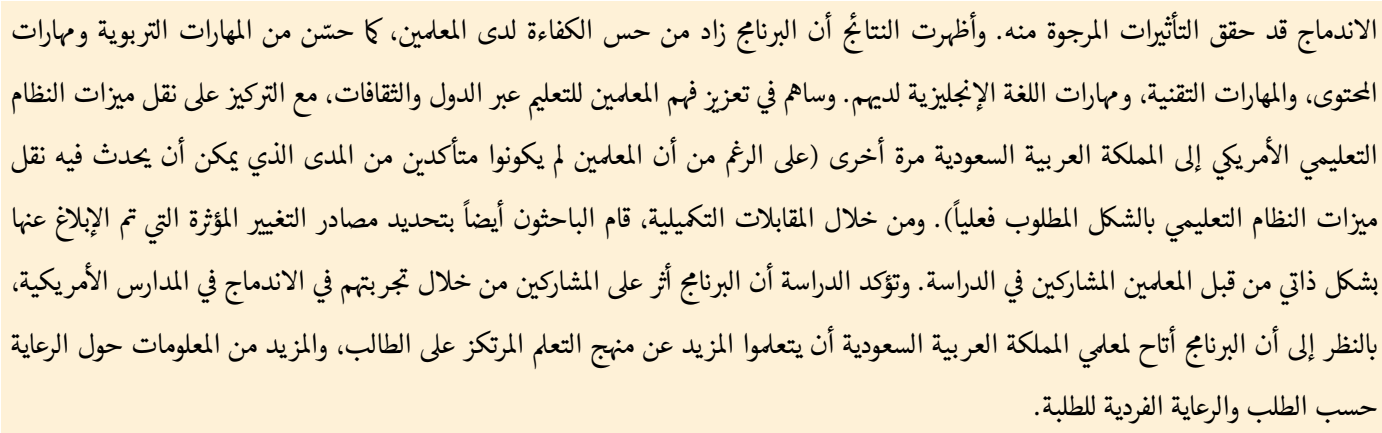

Keywords: Higher education, Professional development program, Immersion program, International partnerships, Kingdom of Saudi Arabia, United States

الكالمات المفتاحية: التعليم العالي، برناجج التطوير المهني، برناجج الاندماج، الثراكة الدولية، المملكة العربية السعودية، الولايات المتحدة الأمريكية.

\section{Introduction}

As globalization in educational reform advances, it has become common practice for more government officials and educational practitioners to seek, in order to transfer, educational reform ideas from foreign nations. While such international collaborations are not new to education, including teacher education (Freeman, 1993, 2009), more recent, dramatic reconfigurations and social transitions have provided greater impetus for varying emerging economies to reform educational systems by learning about and then transferring foreign educational practices, policies, and procedures to home contexts (Darling-Hammond \& Lieberman, 2012; Kabilan, 2013; Kitchen et al., 2019; Lunenberg et al., 2017; Song et al., 2019).

The Kingdom of Saudi Arabia (KSA) is one such case wherein dramatic restructuring of the entire nation and its society is at work, especially as the KSA simultaneously develops ambitious reforms throughout KSA education systems, with primary concerns surrounding KSA's education quality and students' achievement as a driving force for all KSA's current educational reforms. Contrary to KSA's high ambition to compete globally mentioned in its Vision 2030 (KSA, n.d.), Programme for International Student Assessment (PISA) 2018 results, for example, indicated that KSA students' levels of achievement in reading, mathematics, and science were significantly low compared to the average of other comparable Organization for Economic Co-operation and Development (OECD) countries (OECD, 2019). KSA students also displayed lower academic performance when compared with its neighbors, such as United Arab Emirates (UAE), 
Qatar, and Jordan (OECD, 2019). Accordingly, the KSA government wanted to revamp its education system so that they might better secure a skilled workforce for KSA's future, given its increasingly diversified economy. One key reform involved the KSA Ministry of Education (MoE)'s decision to fund and provide intensive, one-year study-abroad professional development programs for its teachers, whereby the MoE set out to send at least 25,000 selected KSA teachers abroad until the year 2030 (Estimo, 2015).

While certainly unique, large, expensive, and intensive, the goal of the KSA MoE program is to raise teacher capacity within and throughout the KSA, which is to also help contribute to the overall reform of the KSA educational system. Specific objectives of the program are to better prepare KSA teachers, who are collectively focused on developing values, knowledge, skills, and attitudes of KSA children, all in support of a more diverse economy, and a more prosperous and flourishing future for KSA. Moreover, the MoE of the KSA expects to develop teachers into agents of change who will subsequently lead educational innovations and transformations throughout the KSA.

\subsection{Study context}

One of the universities the KSA is currently collaborating with to meet the aforementioned goals and objectives is a large, research-intensive university located in the southwest United States (US). The college of education within this university received a grant funded by the KSA MoE for the study-abroad, professional development program. The basic design of this program was to provide one year of teacher training and field immersion for K-12 teachers from the KSA within local school districts around the university's greater metropolitan area. Training was to primarily focus on English language learning, as necessary for the immersion experiences, and the development of content, pedagogical, and technical knowledge and skills, via guided immersion and program courses.

For the English learning component, KSA teachers participated in intensive English language learning courses which covered reading, writing, listening, and speaking. To further participants' content, pedagogical, and technical knowledge and skills development, teachers took courses within the college as pertinent to developing teaching methods, practices, and pedagogies, as well as content knowledge. Teacher participants also engaged in special workshops and conferences to enhance their technological capacities, increase their leadership capacities as change makers, and learn about the US education system, to hopefully transfer best practices pertaining to social inclusion, social justice, and the like back to the KSA. 
Finally, the guided immersion component included field work within K-12 classrooms and a one-to-one mentoring program with educational leaders which offered teachers a chance to reflect upon their educational experiences and practices. Teachers' actual immersion experiences transpired for approximately seven months, starting after an initial set of English language learning and pedagogical trainings. For the latter twoto-three months of this time, teachers spent $30 \mathrm{hr} /$ week and $7.5 \mathrm{hr} /$ day from Monday to Thursday at each of their assigned schools for their full immersion experiences. Every participant was placed into a classroom, as matched with a teacher, and mentor (e.g., in that the teacher mentor was to support each KSA teacher via observation, dialogue, professional advice) by subject area(s) and grade level(s) taught, as per KSA participants' corresponding roles in their KSA schools. In addition, the KSA teachers had multiple opportunities to teach students in person; however, their experience and time commitments did vary depending on their partnering teachers and schools in which they were placed. Moreover, KSA participating teachers' experiences were also facilitated by educational experts including professors from the college of education, wherein KSA teachers received most of their pedagogical training.

\subsection{Purpose}

In this study, we collaborated with program leaders to capture and assess the intended and unintended effects of this program. More specifically, we evaluated the program impact as an independent external evaluation team. The goal was to, as aligned with the more detailed outcomes of the program, examine KSA teacher participants' changes in: (1) teacher efficacy; (2) program-specific outcomes including, for example, classroom management skills, content-specific knowledge, pedagogic skills, and English language pedagogies and skills; and (3) cross-national educational understandings, defined as elements of any foreign education system that can be both understood and mobilized to help enhance educational system in one's home country (Phillips, 2006). More specifically of focus here were KSA participants' views and understandings of both nations' educational philosophies, typical school cultures, educational policies, curricula, and pedagogical techniques. Increased understandings in these areas were to ultimately help mobilize this knowledge and transfer back to KSA the skills learned, after teachers returned to the KSA. We assessed each of these areas of interest to determine whether the expected outcomes noted were achieved via this study-abroad program.

In addition, we tried to capture KSA teachers' (4) sense making and understandings of KSA's goals for this global approach to education reform; (5) critical incidents, including 
memorable events realized throughout the program; and (6) future plans including, for example, KSA teachers' plans for transferring and applying learnings back in the KSA.

Congruently, the following five research questions guided this study: How did participating in the program:

(1) impact KSA teachers' levels of teacher efficacy?

(2) influence KSA teachers' technical competencies as related to program-specific outcomes, including in KSA teachers' English proficiency and by subject area taught?

(3) influence KSA teachers' cross-national educational understandings and mobilization of knowledge and transferability of skills learned?

In addition, albeit not as explicitly anticipated by the KSA MoE, the study also examined

(4) What KSA teachers' most memorable events/moments (i.e., critical incidents) were in terms of their professional development while immersed in the US?

(5) What might the KSA teachers do or not do when they return to their schools in KSA, as per their current understandings of the KSA's educational reform efforts and their learning experience in the US?

This study generally defined this program as a study-abroad, immersive, professional development program designed for teachers whose home nation is undergoing significant and widespread governmental transitions and economic transformations. We defined the specific components of the program and desired effects alongside the key outcomes (as detailed via research questions (1)-(3) above). Figure 1 indicates the overall theoretical framework and its relevant research questions (1)-(3). It is important to note again that research questions (4) and (5) were supplementary, or rather, not of specific interest to anyone beside us and leaders of the college of education where the program and study took place.

For teacher efficacy, an instrument aligned with Tschannen-Moran's and Hoy's (2001) instrument was used, in order to, overall and by subconstruct as related to teacher efficacy, help measure this particular program's effects.

On the other hand, the program-specific outcomes suggested by the KSA provided us with another framework or lens to work with. More specifically, the KSA government provided very detailed program outcomes to which program developers aligned all facets of this program and to which we aligned the research questions. 


\section{Figure 1}

Theoretical framework

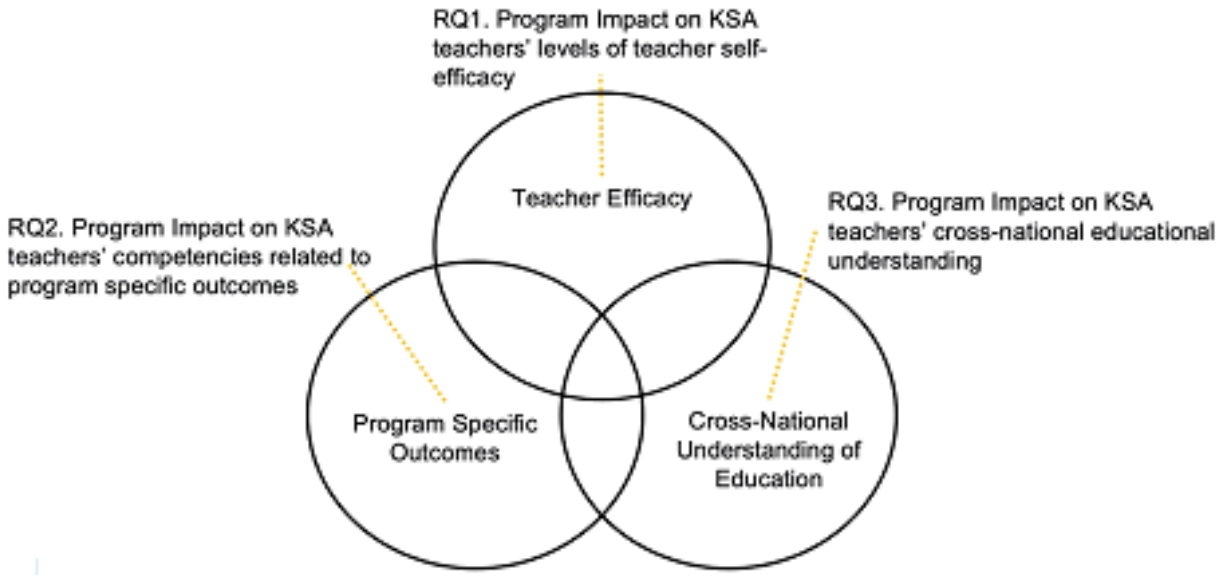

For example, for KSA's non-English subject area teachers, the KSA government asked for improvement in areas and skills that were slightly albeit substantively different from that desired by the KSA government of its English subject area teachers. However, all general outcomes were still framed around the following general tenets (again, as differentiated by the English or non-English subject area of KSA teachers): (1) the extent to which KSA teachers anticipated and knew how to effectively respond to difficulties when teaching; (2) the extent to which KSA teachers recognized the importance of, gained a certain level of knowledge in, and increased self-confidence in the program outcome areas; and (3) the extent to which KSA teachers gained a comparative understanding of the KSA education system in comparison to that of the US. Of related importance was in what ways, if any, (4) KSA teacher participants believed those involved in the education system in the US might learn from the KSA in order to make improvements in the US education system, and vice versa. We, accordingly, aligned all questions as well as instruments, in general and by teacher type when required, to all the aforementioned tenets (see, for example, Appendices A and B, in an anonymous Word document located in Google Drive here, for more details capturing these larger goals and ideals).

Given the program's goal to transfer advanced educational features of the US back to the KSA, we also adopted a framework pertaining to building cross-national understandings. More specifically, this framework helped direct the research when measuring transformation, in this case of KSA teacher participants' understanding of education across nations and cultures, with emphasis on the transfer of features of the US educational system back to the KSA. However, in the interests of strategic alliances, as well as mutual beneficence (Todeva \& Knoke, 2005), it was important to all involved that an inverse flow of information and transfer also be possible, valued, and assessed in terms of this study. 
Hence, cross-national understandings were also a critical component of this study. In order to measure the depth of cross-national understanding of education, we adopted the concept of "foci of attraction" identified by Philips (2006) that includes six distinctive units of borrowable elements of foreign educational systems (i.e., guiding philosophies, ambitions and goals, policies, enabling structures, processes, and techniques).

\section{Literature Review}

Immersive experiences are known to have critical impacts on learning. Glaser (1978), for example, emphasized the value of immersive experiences on gaining contextual knowledge and new perspectives, whereby immersion in and of itself, can be translated as a critical part of teacher education developing teachers' pedagogic belief and competency through learning-by-doing (Tillema, 2000). Such an immersion experience also has an impact on intercultural learning (Canfield et al., 2009; Tomlinson『Clarke \& Clarke, 2010). Canfield et al. (2009) noted that immersive intercultural learning promotes understanding of foreign cultures as well as own cultures in effect. Likewise, there is increasing popularity of immersive study-abroad programs, especially in this context for in-service teachers' professional development

Related, and perhaps given such programs' increasing popularity (Kaszuba, 2018), the impact of immersive study-abroad programs for teachers and on teacher thought and practice is under close examination. However, studies conducted thus far have mostly examined immersive study-abroad programs for pre-service teachers (Brindley et al., 2009; Lee, 2011; Okken et al., 2019; Pence \& Macgillivray, 2008; Rodriguez, 2012), focusing mainly on teachers' intercultural competencies and mindsets (Cushner, 2007; Sharma et al., 2011; Yeo \& Yoo, 2019). In addition, studies have often examined the effects of immersive study-abroad programs on the English acquisition of foreign language teachers (Gleeson \& Tait, 2012; Cook, 2010), or foreign language acquisition in general (Kaszuba, 2018). Consequently, there is much room to explore, in order to better understand the impact of immersive study-abroad professional development programs for teachers and on teachers.

Teacher efficacy is a critical measure explaining the level of teacher's competency or impact of teachers' education and training. Teacher efficacy is a concept derived from the notion of self-efficacy, as conceptualized by Bandura (1977, 1982), who argued that human knowledge and recognition is not necessarily translated into human action but mediated through self-referent thoughts about one's own capabilities or, rather, perceptions of their capabilities defined as efficacy (Bandura, 1982). In teacher education, teacher efficacy has been understood as a critical predictor of action that 
helps to explain and understand teaching performance in the classroom, in addition to its subsequent effects on student learning and achievement (Ashton \& Webb, 1986; Mahler et al., 2018; McCoach \& Colbert, 2017). Accordingly, teacher efficacy is often used to measure program effectiveness for teachers engaged in multiple professional development programs, international and local (Cantrell \& Hughes, 2008; Postareff et al., 2007; Tschannen-Moran \& McMaster, 2009).

There are many different versions of teacher efficacy measures (Bandura, 2006; Gibson \& Dembo, 1984; Skaalvik \& Skaalvik, 2007), but one of the most well-known is the one developed by Tschannen-Moran and Hoy (2001). In developing their instrument, Tschannen-Moran and Hoy (2001) engaged in a thorough review of the literature, as well as a systematic development and validation process, so that their framework and resulting instrument might help capture three main constructs of teacher efficacy: teachers' (1) instructional strategies, (2) classroom management skills, and (3) effectiveness when engaging students in learning. Hence, using this instrument allows the measurement of multiple levels of teacher efficacy through teachers' self-reported levels of confidence per question item. In addition, this instrument has been evidenced to produce consistent results across different countries (Klassen et al., 2011).

Cross-national understanding of education is a critical component to trigger educational transfer, mobilizing education system and practice from one country to another. Philips (2006) suggested the concept of "foci of attraction" to explain the universal process of educational transfer based on the interactions between the contents and context related to the transfer event. According to his idea, the "foci of attraction" consists of six distinctive units of borrowable elements of foreign educational systems (i.e., guiding philosophies, ambitions and goals, policies, enabling structures, processes, and techniques), insisting that most educational transfer happens to borrow these six educational features from the foreign countries. In previous studies of educational transfer, researchers have evidenced that some educational features tend to be transferred from one context to another without enough cross-national understandings of education, thus failing to help teachers settle into the practices of others and from one another, also in international contexts (Nir et al., 2017; Tan, 2016).

\section{Methodology}

We used a program-oriented approach to conduct this study, which means that we aligned the study's objectives and outcomes as written by the grant program's sponsor (i.e., the KSA MoE) to their research questions, as well as study design (Fitzpatrick et al., 2011). In addition to assessing official program objectives, we assessed which program 
component(s) were most memorable and influential, as per the self-reported responses of the KSA teacher participants involved, to also get feedback on the overall program and its design. These additional interests afforded a more practical and participatory approach, whereas the elements of the study were designed collaboratively between us, college leaders, and KSA leaders, to ultimately improve programming and understand the multiple realities experienced by KSA teacher participants throughout this immersion program (Fitzpatrick et al., 2011).

The evidence of change in the above domains was collected using three different sets of mixed methods: pre- and post-surveys, pre- and post-English tests, and selective in-depth interviews.

\subsection{Pre- and Post-survey}

\subsubsection{Method}

With intention to capture the effect of the program's intervention, we adopted a onegroup, pretest-posttest design, which is a quasi-experimental design method (i.e., given there were no comparison groups that we could compare KSA participants' impacts with).

\subsubsection{Sample}

In total, $46 \mathrm{KSA}$ teacher participants were selected as a sample for this study, which represented the entire population of those involved in this program. The sample population included 27 (59\%) English subject area teachers and 19 (41\%) non-English subject area teachers. The response rate for the pre-survey was $91 \%(42 / 46)$, and the response rate for the post-survey was $87 \%$ (40/46), which is well over the response rate (e.g., $70 \%)$ needed to yield valid findings (Nunnally, 1978; Nulty, 2008).

\subsubsection{Instrument}

Two survey instruments were used, different only by language of the KSA participants (i.e., non-English and English subject areas), each with three different sections pertaining to KSA teacher participants' levels of (1) teacher efficacy, (2) program-specific outcomes, and (3) cross-national understandings of education. 


\section{Table 1}

KSA teacher survey Cronbach's alpha (pre-post combined

Constructs
Teacher efficacy
Recognition of importance of technical
competencies
Knowledge of theories and models
Self-confidence in technical competencies
Cross-national understandings of US education
Mobilization of knowledge and transferability of
skills
Overall alpha

\begin{tabular}{|c|c|}
\hline \multicolumn{2}{|c|}{ Coefficient alpha } \\
\hline English teacher & Non-English teacher \\
\hline 0.80 & 0.84 \\
0.86 & 0.91 \\
\hline 0.83 & 0.92 \\
0.87 & 0.91 \\
0.96 & 0.95 \\
0.90 & 0.93 \\
\hline & 0.95 \\
\hline
\end{tabular}

The instruments included 58 Likert-type items with scales ranging from "a great deal" $=5$ to "not at all" $=1$, "strongly agree" $=6$ to "strongly disagree" $=1$, and "yes" = 3 , "unsure" $=2$, and "no" $=1$.

The surveys were constructed, piloted, revised, and then distributed using the electronic software, Qualtrics (2019), following which the same surveys were used on the pretest and post-test occasions (i.e., when KSA participants entered the immersion program and upon their completion). Please see the survey instruments listed in Appendix A (for non-English subject area teachers) and Appendix B (for English subject area teachers).

\subsubsection{Data analysis}

After the post-survey administration, the internal reliability of the survey instrument was assessed by construct and overall using Cronbach Alpha tests (Cronbach, 1951; Tavakol \& Dennick, 2011). The goal here was to ensure that levels of internal integrity or consistency existed amongst the components within the same constructs and overall, within this survey instrument. Construct- or overall-alphas should exceed 0.7, as per Tavakol and Dennick (2011) to guarantee that both survey instruments are functioning as designed and intended. All by-construct and overall alpha levels met this threshold. Table 1 presents alpha levels by construct and overall.

Further, we measured the degree of change in participants' responses, again, on the same survey instrument, from the pre- to post-tests occasion. More specifically, we analyzed participants' pre- and post-tests responses by item, per section of the survey, as illustrated in Table 2, and overall, using $t$-tests in order to assess the extent to which 
Table 2

Research questions and survey constructs

\begin{tabular}{l|l}
$\begin{array}{l}\text { RQ1. Impact on KSA } \\
\text { teachers' levels of teacher } \\
\text { self-efficacy }\end{array}$ & $\begin{array}{l}\text { RQ2. Influence on KSA teachers' } \\
\text { technical competencies as related to } \\
\text { program-specific outcomes, } \\
\text { including in KSA teachers' English } \\
\text { proficiency and by subject area } \\
\text { taught }\end{array}$ \\
$\begin{array}{l}\text { Construct2. Teachers' technical } \\
\text { competencies as related to } \\
\text { efficacy }\end{array}$ & $\begin{array}{l}\text { Sub-construct. Recognition of } \\
\text { importance of technical } \\
\text { competencies } \\
\text { Sub-construct2. Self-confidence in } \\
\text { technical competencies } \\
\text { Sub-construct3. Teacher knowledge } \\
\text { related to various instructional } \\
\text { theories and methods }\end{array}$ \\
\end{tabular}

RQ3. Influence on KSA teachers' cross-national educational understandings

Construct3. Cross-national understandings

Sub-construct1. Cross-national understandings of US Education Sub-construct2. Mobilization of knowledge and transferability of skills

a statistically significant change in participants' perceptions across all three constructs might have occurred post program.

A null hypothesis $\left(\mathrm{H}_{0}\right)$ was set to represent no difference in the mean scores of preand post-survey results, and an alternative hypothesis $\left(\mathrm{H}_{a}\right)$ was set as having differences in the mean scores of pre- and post-survey results.

$$
\begin{aligned}
& \mathrm{H}_{0}: d=0 \\
& \mathrm{H}_{a}: d^{1} \mathrm{O},
\end{aligned}
$$

where $d=$ the mean score of post-survey - the mean score of pre-survey.

We also calculated effect sizes, using Cohen's $d$ (Cohen, 1988, 1992), in order to quantify the practical difference, or pragmatic change between the pre- and post-tests on the same indicators. In social science research, Cohen suggested that if $d=0$, the practical significance of any difference be considered "trivial," and that a $d=0.2$ be considered a "small" effect size; $d=0.5$ a "medium" effect size; $d=0.8$ a "large" effect size; and anything over $d=1.0$ as a "very large" effect size.

\subsection{English test}

\subsubsection{Method}

We were also interested in finding the effects of the program intervention on the improvement of KSA participants' English skills. Thus, another one-group pre-posttest 
design, akin to the quasi-experimental design used for the survey described prior, was used.

\subsubsection{Sampling}

All 46 participants took the pre-English test, and 45 participants took the post-test, yielding one less participant from the pre- to posttest occasions (i.e., $2 \%$ attrition).

\subsubsection{Instrument}

The English tests were created and administered by ASU Global Launch, which is the university's platform that provides (among many services) language training for international students.

\subsubsection{Data analysis}

$T$-tests with dependent samples were calculated, wherein each pretest was matched with the posttest, given the same population samples. Again, a null hypothesis $\left(H_{0}\right)$ was set to indicate no difference in the mean score of pre- and post-tests results, and an alternative hypothesis $\left(\mathrm{H}_{a}\right)$ to indicate a difference in the mean score of pre- and post-tests results.

$$
\begin{aligned}
& \mathrm{H}_{0}: d=0 \\
& \mathrm{H}_{a}: d^{1} \mathrm{O},
\end{aligned}
$$

where $d=$ the mean score of post-test - the mean score of pre-test.

Effect sizes were also calculated again, and as described prior.

\subsection{Interviews}

\subsubsection{Method}

Interviews with the KSA participants were conducted to examine, more in-depth and as aligned with research questions (4) and (5), participants' (4) critical incidents, including memorable events in the program, and (5) future plans as an indicator of program impact. Put differently, we identified which program components were perceived as influential by participants and why, following which participants' future plans were recognized and the values, ideas, practices, and knowledge that might be registered and then transferred back to the KSA were extracted. 


\subsubsection{Sampling}

The study used a convenience sampling process (Merriam \& Tisdell, 2016; Stake \& Trumbull, 1982), ultimately selecting five interviewees who were available during the study period, and who were also comfortable with their English proficiency given all interviews were conducted in English. Because the interviewee sample size was too small to represent the view of the entire population of KSA participants, the goal of this part of the study was not to generalize.

\subsubsection{Instrument}

The interview protocol included a total of five interview questions organized, again, under constructs pertinent to the study's last two research questions: (4) critical incidents, including memorable events in the program, and (5) future plans as an indicator of program impact. The interviews were conducted in the university campus during the final days of the program, with each interview taking approximately 30-60 min. Researchers recorded the interviews for transcription purposes (see Appendix $C$ for the interview protocol).

\subsubsection{Data analysis}

The interview data were categorized across the five participants into each of the given question topics. Data were coded in order to create thematic nodes, which represented specific common themes that were used to bind multiple statements together (Merriam \& Tisdell, 2016). Thereafter, the NVivo 12 software was used to create certain thematic nodes.

\section{Results}

\subsection{Pre- and Post-survey}

KSA teacher participants' self-reported levels of efficacy increased from pre- to postsurvey for both the English language subject area teachers and non-English language subject area teachers. While, in the end, the non-English language subject area teachers rated their confidence slightly higher than the English language subject area teachers, the observed changes of the English language subject area teachers' self-efficacy were both statistically significant (meaning that the results were not due to chance) and 
Table 3

T-tests for teacher efficacy from pre- to post-survey

\begin{tabular}{|c|c|c|c|c|}
\hline & \multicolumn{2}{|c|}{ English } & \multicolumn{2}{|c|}{ Non-English } \\
\hline & $\mathbf{M}$ & SD & $M$ & SD \\
\hline \multirow{2}{*}{$\begin{array}{l}\text { Pre-survey } \\
\text { Post-survey }\end{array}$} & $4.07^{*}$ & 0.38 & 4.20 & 0.32 \\
\hline & $4.27^{*}$ & 0.46 & 4.45 & 0.47 \\
\hline Effect size & \multicolumn{2}{|c|}{0.47} & \multicolumn{2}{|c|}{0.62} \\
\hline
\end{tabular}

${ }^{*} p<0.05$ significance level

practically significant ( $d=0.47$; a "moderate" effect size). The increase for non-English language subject area teachers was statistically significant, and the effect size observed was larger ( $d=0.62$; "moderate"; see also Table 2).

KSA teacher participants also reported an increase in the recognition of the importance of their technical competencies from the pre- to post-survey, with the average response from KSA teacher participants falling between "agree" and "strongly agree." This indicated that this group of program participants recognized the importance of and were relatively more cognizant over time of the importance of the technical competencies built into this immersion program. In this case, however, neither of the observed mean differences observed were statistically significant, and both sets of subject area teachers yielded "trivial" effect sizes over time (e.g., $d=0.10$ and 0.20 , respectively; see also Table 3).

In terms of KSA participants' reported levels of self-confidence, as related to the same set of technical competencies, again, only KSA teacher participants who taught English reported an increase in said self-confidence. Neither of these differences were statistically significant, and the reported growth in self-confidence among English subject teachers was moderate in effect $(d=0.50)$. Inversely, KSA teacher participants who taught a subject area other than English reported a decline in their self-confidence in this area. While this decline was also not statistically significant, the effect size was negative, albeit "trivial" ( $d=-0.11$; see also Table 3 ).

While both English and non-English subject area teachers reported that they were mostly familiar with instructional theories and methods used to support their technical competencies, the non-English subject area teachers reported that they were slightly more knowledgeable in the end (see Table 5). Likewise, the increase observed among non-English subject area teachers were both statistically and practically significant ( $d$ = 0.50; "moderate"). hereof note, both groups of KSA teacher participants reported 


\section{Table 4}

T-tests for teacher beliefs on technical competencies

\begin{tabular}{|c|c|c|c|c|}
\hline & \multicolumn{2}{|c|}{ English } & \multicolumn{2}{|c|}{ Non-English } \\
\hline \multicolumn{5}{|c|}{ Recognition of importance of technical competencies } \\
\hline & M & SD & $\mathbf{M}$ & SD \\
\hline \multirow{5}{*}{$\begin{array}{l}\text { Pre-survey } \\
\text { Post-survey Effect } \\
\text { size }\end{array}$} & 5.69 & 0.31 & 5.38 & 0.56 \\
\hline & 5.73 & 0.43 & 5.49 & 0.52 \\
\hline & \multicolumn{2}{|c|}{0.10} & \multicolumn{2}{|c|}{0.20} \\
\hline & \multicolumn{3}{|c|}{ Self-confidence in technical competencies } & \\
\hline & $\mathbf{M}$ & SD & $\mathbf{M}$ & SD \\
\hline \multirow{2}{*}{$\begin{array}{l}\text { Pre-survey } \\
\text { Post-survey }\end{array}$} & 5.30 & 0.57 & 5.47 & 0.49 \\
\hline & 5.55 & 0.41 & 5.40 & 0.71 \\
\hline Effect size & \multicolumn{2}{|c|}{0.50} & \multicolumn{2}{|c|}{-0.11} \\
\hline
\end{tabular}

${ }^{*} p<0.05$ significance level

\section{Table 5}

T-tests for teacher knowledge related to various instructional theories and methods

\begin{tabular}{|c|c|c|c|c|}
\hline & \multicolumn{2}{|c|}{ English } & \multicolumn{2}{|c|}{ Non-English } \\
\hline \multicolumn{5}{|c|}{ Knowledge of theories and models } \\
\hline & M & SD & M & SD \\
\hline \multirow{2}{*}{$\begin{array}{l}\text { Pre-survey } \\
\text { Post-survey }\end{array}$} & 2.57 & 0.43 & $2.61^{*}$ & 0.52 \\
\hline & 2.78 & 0.30 & $2.82^{*}$ & 0.28 \\
\hline Effect size & \multicolumn{2}{|c|}{0.56} & \multicolumn{2}{|c|}{0.50} \\
\hline
\end{tabular}

${ }^{*} p<0.05$ significance level

increase in their knowledge of instructional theories and methods at a "moderate" level of effect ( $d=0.56$ for the English subject area language teachers).

KSA teacher participants also reported an increase in their understandings of the US education system, as well as in their potential mobilization of knowledge and transferability of skills learned. More specifically, English subject area teachers yielded a statistically significant increase in their cross-national understanding of the US education system, also yielding a "very large" effect size $(d=1.07)$. Put differently, for the English subject area teachers, the immersion program apparently provided a very clear increase in their cross-national understandings of education. Non-English subject area teachers were, however, more likely to agree that they understood the US education system 
Table 6

T-tests for teacher cross-national understandings

\begin{tabular}{|c|c|c|c|c|}
\hline & \multicolumn{2}{|c|}{ English } & \multicolumn{2}{|c|}{ Non-English } \\
\hline \multicolumn{5}{|c|}{ Cross-national understandings of US education } \\
\hline & $\mathbf{M}$ & SD & M & SD \\
\hline \multirow{2}{*}{$\begin{array}{l}\text { Pre-survey } \\
\text { Post-survey }\end{array}$} & $3.59 * *$ & 1.40 & 4.40 & 0.91 \\
\hline & $4.82^{* *}$ & 0.81 & 4.93 & 0.71 \\
\hline Effect size & \multicolumn{2}{|c|}{1.07} & \multicolumn{2}{|c|}{0.64} \\
\hline \multicolumn{5}{|c|}{ Mobilization of knowledge and transferability of skills } \\
\hline \multirow{2}{*}{$\begin{array}{l}\text { Pre-survey } \\
\text { Post-survey }\end{array}$} & 4.45 & 0.61 & 4.69 & 0.72 \\
\hline & 4.45 & 0.75 & 4.45 & 1.20 \\
\hline Effect size & \multicolumn{2}{|c|}{0} & \multicolumn{2}{|c|}{-0.24} \\
\hline
\end{tabular}

${ }^{* *} p<0.01$

before and after the immersion experience (see Table 5), however the increase they posted were not statistically significant and not as practically significant $(d=0.64$; "moderate") as the English subject area teachers.

In terms of KSA participants' perceptions of their mobilization of knowledge and transferability of skills, no change was reported in the perceptions among both the English and non-English subject area teachers. Indeed, non-English subject area teachers were slightly less likely to report increased beliefs in their abilities or capacities to mobilize or transfer skills from the US to KSA at the completion of the program. However, none of these results were statistically or practically significant $(d=0$ and $d=-0.24$; see Table 5).

In addition to the Likert-scale constructs, the post-survey contained two open-ended questions used to ask KSA participants in what ways they thought that educational features could be transferable from the KSA to the US, and from the US to the KSA. For the first question, participants most frequently responded that the US could learn from the KSA when it comes to respecting the teaching profession and paying teachers better salaries. A few KSA scholars also mentioned the issue of discipline, noting that US teachers could either prohibit student punishment completely or ensure discipline is done in a way that respects both teachers and students.

With regards to what ways KSA participants thought educational features could be transferred from the US to the KSA, respondents most frequently mentioned that the abundance of technology within the US education system (as they experienced via 
their immersion experiences) was the most desirable feature to borrow, especially in terms of how US teachers appeared to have access to and use various technologies, regardless of the content or subject areas taught. Also, the KSA respondents considered the decentralized and autonomous school system as a very attractive feature of the US educational system. Reportedly most intriguing to the KSA participants, however, were things like teacher professional learning communities (PLCs; Dana \& Yendol-Hoppey, 2015; Snow-Gerono, 2005) and opportunities to collaborate with other teachers within and across schools in a district setting. The KSA teacher participants also mentioned US assessment systems, and that various assessment and teaching methodologies would also be highly valuable in the KSA.

Finally, when we looked at the entire survey and examined KSA teacher participants' overall changes, we found, on average, that KSA teacher participants increased their scores from pre- to post-survey across the board. The increases observed were statistically significant for both the English and non-English subject area teachers. However, the positive effect size was relatively larger for the English subject area teachers $(d=0.41)$ versus the non-English language subject area teachers ( $d=0.16$; see Table 6$)$. This finding was, more or less, commensurate with the by-construct findings noted earlier; that is, while all KSA teacher participants seemed to gain in their desired outcomes over time, overall, the program interventions worked slightly better for the English subject area teachers versus the non-English subject area teachers as per KSA teacher participants' self-reported (1) levels of teacher efficacy, (2) program-specific outcomes, and (3) crossnational understandings of education for KSA teacher participants (see Table 6). While, again, English language teachers had higher overall scores, this potentially indicates that English proficiency may have impacted participants' immersion experiences. Put differently, the extent to which participants knew and understood English seems to have had an impact on the effects experienced by KSA participants throughout this program; although, we did not examine the extent to which varying and changing levels of English proficiency were correlated with or caused the differentiated gains noted. This was only noted as an important consideration here, also given obvious implications for others considering similar program upon which English proficiency relies. The primary language of instruction and use throughout any immersion setting or program matters. 


\section{Table 7}

T-tests for survey overall

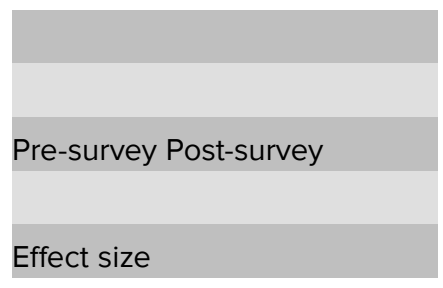

${ }^{*} p<0.05$ significance level

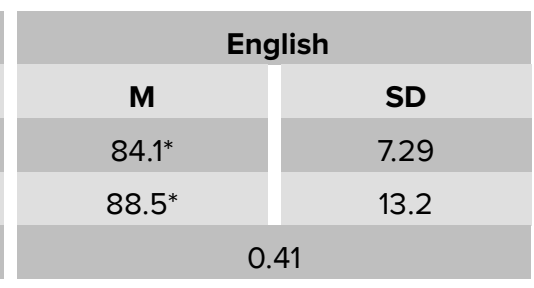

\begin{tabular}{|c|c|}
\hline \multicolumn{2}{|c|}{ Non-English } \\
\hline M & SD \\
\hline $59.5^{*}$ & 26.9 \\
\hline $64.0^{*}$ & 27.0 \\
\hline \multicolumn{2}{|c|}{0.16} \\
\hline
\end{tabular}

\subsection{English test}

Strong evidence that the English language instruction provided by [name of organization removed for peer review] improved KSA teacher participants' English language proficiency, again, as measured and assessed through listening and reading (including grammar, vocabulary, reading comprehension) and speaking (including grammar, syntax, usage and picture identification) was observed. Each of the elements assessed via the English test was seen to have a practical significance with trivial effect sizes (e.g., $d=0.27-0.48$; see Table 7).

As illustrated in Table 7, researchers observed statistically significant increases on all scores as measured from pre- to post-English assessments at a significance level of $p<0.05$. More specifically, this means that KSA teacher participants answered almost four more questions correctly on the post-assessment than they did on the pre-assessment. They added 2.5 more words to their narrative writing, asked about one more question during dialogic conversations, and their post reading and writing scores increased by six and seven points, respectively, from their pre- to postassessments.

\subsection{Interviews}

\subsubsection{Critical incidents}

Researchers' coding of KSA participants' interview transcripts yielded three unique topics related to the critical experiences. Table 9 illustrates the distribution of coding across four topics and five teacher interviewees.

Four of the five KSA teacher interviewees selected their school immersion experiences as the most memorable experiences during the program period. One of the 
Table 8

Descriptive statistics and t-test results for English proficiency tests

\begin{tabular}{|c|c|c|c|c|c|c|c|c|c|}
\hline \multirow[b]{2}{*}{ Outcome } & \multicolumn{2}{|c|}{ Pre-test } & \multicolumn{2}{|c|}{ Post-test } & \multicolumn{5}{|c|}{$95 \% \mathrm{Cl}$ for mean difference } \\
\hline & $\mathbf{M}$ & SD & $\mathbf{M}$ & SD & $\mathbf{n}$ & & $\mathbf{r}$ & $\mathbf{t}$ & $\begin{array}{c}\text { Effect } \\
\text { size }\end{array}$ \\
\hline $\begin{array}{l}\text { Answering } \\
\text { Questions }\end{array}$ & 33.56 & 6.68 & 37.37 & 4.86 & 42 & $2.52,4.85$ & $0.84^{*}$ & $6.41^{*}$ & 0.65 \\
\hline $\begin{array}{l}\text { Extended } \\
\text { Narrative }\end{array}$ & 24.02 & 7.44 & 26.84 & 6.55 & 43 & $1.07,4.24$ & $0.73^{*}$ & $3.38^{*}$ & 0.40 \\
\hline $\begin{array}{l}\text { Question } \\
\text { Formation }\end{array}$ & 12.38 & 3.07 & 13.23 & 3.21 & 43 & $0.05,1.49$ & $0.73^{*}$ & $2.14^{*}$ & 0.27 \\
\hline Speaking & 70.22 & 15.42 & 76.67 & 14.06 & 46 & $4.34,8.57$ & $0.89^{*}$ & $6.15^{*}$ & 0.44 \\
\hline Reading & 53.04 & 17.04 & 60.52 & 13.71 & 46 & $4.48,10.47$ & $0.81^{*}$ & $5.03^{*}$ & 0.48 \\
\hline
\end{tabular}

${ }^{*} p<0.05$

Table 9

Critical incident

\begin{tabular}{l|c|c|c|c|c|} 
& Interviewee 1 & Interviewee 2 & Interviewee 3 & Interviewee 4 & Interviewee 5 \\
\hline Pedagogic training & 0 & 0 & 0 & 1 & 2 \\
\hline School immersion & 4 & 4 & 3 & 7 & 0 \\
\hline $\begin{array}{l}\text { Experience as a } \\
\text { parent }\end{array}$ & 0 & 0 & 0 & 0 & 1 \\
\hline
\end{tabular}

interviewees pointed out that the school immersion experience was truly a moment of mobilization, stating:

When I was in school immersion, there was the transfer and reflect (of the educational system and practice in the US) that we have different educational system [in KSA].

The interviewees also chose to discuss different aspects of that which they observed in practice as valuable during their school immersion experiences. These esteemed experiences were noted, also in no particular order, as centered around customized learning, the uses of new educational technologies, the school culture and interpersonal interactions at the teacher-teacher, teacher-student, and student-student levels that participants observed, the varieties of teaching and pragmatic skills learned, and the variety of special programs (e.g., special education, gifted, and science, technology, engineering, and mathematics [STEM]) offered by schools to which so many students had access.

Participants noted that their learning about US education culture and practice happened outside of their systemic program experiences, as well. One of the interviewees 


\section{Table 10}

Future plans

\begin{tabular}{l|c|c|c|c|c|} 
& $\begin{array}{c}\text { Interviewee } \\
\mathbf{1}\end{array}$ & Interviewee 2 & Interviewee 3 & Interviewee 4 & Interviewee 5 \\
\hline $\begin{array}{l}\text { Student-centered } \\
\text { learning }\end{array}$ & 5 & 2 & 1 & 0 & 2 \\
\hline \begin{tabular}{l} 
Pedagogic innovation \\
\hline
\end{tabular} & 0 & 2 & 0 & 1 & 1
\end{tabular}

who brought their children to the US, for example, mentioned that they learned from the way their own children's teachers were actively engaged with personal learning, saying:

My kids like to ask questions and the teacher answered for them. Some questions were not acceptable in Saudi Arabia, [with] teachers saying, "Go to your mom and ask her." But here the teachers accept them ... Their experiences also influenced me.

This means that not only the program intervention but also cross-cultural experience outside of the formal program influenced and shaped these participants' understandings of the US education system.

In addition, the participants also learned via the college of education's pedagogic training courses. One of the interviewees, for example, discussed how taking classes in the college brought new, transformative knowledge which opened their eyes into new teaching skills, attitudes, and knowledge, mentioning:

I like the perspective and the concept of learning how they teach at [the university, including the] training of trainers, development of change makers ... and [given the] many classes about differentiation [techniques].

\subsubsection{Future plans}

When asked about the participants' future plans when they went back to KSA, given their understanding of the country's current education reform as well as their learning and immersion experiences in the US, the five teacher interviewees produced two different thematic codes as illustrated in Table 10.

First, four of the five interviewees mentioned that they would adopt student-centered learning aspects. They wanted to try more to respect each student as an individual, having different characteristics and learning styles and preferences, while reducing 
students' workloads and pressures for learning. As an effort to promote the studentcentered learning environment, they planned to focus on improving relationships with their students once back in the KSA. One of them added:

I know when I go back to my school, I will be closer to my students. I will not treat them the way I used to.

They also added that building close relationships was the basic step to provide better education for the students, saying:

When I have ... [a] close relationship with my students, I will be more caring about the students, I will be more caring about their education.

In addition to building or strengthening relationships, two interviewees also said they would try to provide more customized learning for their students using differentiation tactics.

Secondly, three out of five interviewees mentioned that they would like to bring advanced pedagogic and teaching skills to advance KSA's educational quality. One of the interviewees said that they wanted to change the whole education culture in the KSA by using motivation theories learned during the program. Another interviewee wanted to use a variety of pedagogic tools and techniques that could better support improved learning for students, stating:

I can change my way of teaching, method, strategies, and students be more engaging to my lessons. This is what I can change. I saw one of my colleagues here talking of Quizzlab to use and implement in your class. Also, the other thing is Clicker, another way let the students to do the grammar game.

Clearly, and at least as per these interview data, the experiences and knowledge valued most pertained to an increased focus on creating more student-centered learning environments given what KSA participants reportedly observed would help them better serve their students, emotionally, psychologically, and academically.

\section{Discussion}

This study took place at only one of the universities in partnership with MoE of the KSA for the goal of redesigning its national education system. While the findings and outcomes cannot be generalized to all KSA educators who participated in immersion 
programs at various US and Canadian universities (especially given the variance among English language training and, most significantly, the immersion experiences in K12 settings), it seems logical based on our findings to assume that English proficiency would have a significant impact on program outcomes for all KSA participants, regardless of the location of their study-abroad experience. As this program is anticipated to continue through 2030, it is in the best interest of the MoE and KSA participants to have moderate to higher levels of English language proficiency in order to maximize the experiences and opportunities for learning while abroad. This finding could also have implications for other international study-abroad immersion programs where participants are learning in a language other than their first language.

Another point which is important to discuss is the viability of cross-national transfer of pedagogical practices in the first place. One of the survey findings in this study, for example, indicated that enhanced cross-national educational understandings through this immersion experience were not fully translated into intentions to mobilize foreign educational practices. This finding implies that educational transfer is not a straightforward process, especially when transplanting educational practice from one place to another, despite booming best practice modeling approaches to import foreign educational practices from more advanced economies. This may be because immersive experiences can make foreign partners realize contextual barriers when attempting to mobilize such foreign practices within home contexts. This result aligns with literature that suggests that while such partners are not necessarily passive recipients, being proactive creators in the processes of cross-national educational transfer can be more challenging than often more simplistically theorized (Anderson-Levitt, 2003; SteinerKhamsi \& Waldow, 2012).

Finally, this study expanded upon research gaps by examining the impact of an immersive study-abroad professional development program for foreign in-service teachers including the development of intercultural competence, English proficiency, and policy reform understanding and implementation. Findings have implications for others engaging in similar, international, teacher education immersion programs and experiences. Indeed, while language matters in terms of the realization of the goals and objectives of any such program, perhaps the larger, societal, cross-national and -cultural understandings derived via such experiences might matter more. 


\section{Conclusion}

Overall, it appears that participating in this immersion program increased KSA teacher participants' (1) teacher efficacy, (2) program-specific outcomes, and (3) cross-national understandings of education, as well as the mobilization of knowledge and transferability of skills learned for KSA teacher participants. More specifically, in terms of research question 1-How did participating in the program impact KSA teacher's level of teacher efficacy?-researchers found the program increased teacher participants' levels of efficacy, and the increases observed, again, between pre- and post-survey results, was statistically and practically significant at a moderate level for both English and non-English KSA teacher participants.

For research question (2)-How did participating in the program influence KSA teachers' technical competencies as related to program-specific outcomes, including in KSA teachers' English proficiency and by subject area taught?-researchers also found improved teachers' pedagogical, content, technical, and English skills. More specifically, reported recognitions of importance, self-confidence, and knowledge of theory related to program-specific competencies generally increased with trivial or moderate effect size; although, non-English KSA teacher participants' self-confidence slightly decreased. Observed increases in English proficiency were statistically and practically significant at a moderate level for both English and non-English subject teachers.

For research question (3)-How did participating in the program influence KSA teachers' cross-national educational understandings and mobilization of knowledge and transferability of skills learned?-researchers found enhanced teachers' understandings of education across nations and cultures, with emphasis on the transfer of features of the US educational system back to the KSA (although teachers' were uncertain about the extent to which the transference desired might actually occur, given their desires to adopt foreign education system practices did not increase after program completion, and rather slightly decreased). Given that English-language teachers demonstrated higher overall increases, this possibly indicated that English proficiency may have impacted participants' immersion experiences. Put differently, the extent to which participants knew and understood English seems to have had an interactive impact on that which was experienced by KSA participants throughout this immersion program.

Lastly, through interviews with a handful of KSA teacher participants, researchers warranted two overall findings. First, in terms of research question (4)-What KSA teachers' most memorable events/moments (i.e., critical incidents) were in terms their 
professional development while immersed in the US?-KSA teacher participants commonly selected the immersion experience as the most inspiring and motivating source of learning through the program. Second, when asked about transferring knowledge back to the KSA related to research question (5)-What might the KSA teachers do or not do when they return to their schools in KSA, as per their current understandings of the KSA's educational reform efforts and their learning experience in the US?-teacher participants responded that they would focus on building student-centered teaching approaches to improve the educational experiences for each of their students when back in the KSA.

Findings confirmed that immersion learning, providing learning-by-doing opportunities, has a critical impact on teachers' pedagogical capacity building, as teacher efficacy and technical confidence yielded statistically significant increases. In addition, this yearlong study-abroad immersion program helped participants gain a more balanced view on their own culture and society. Likewise, survey results showed that participants did not blindly accept the US education system and practices to which they were exposed and in which they were immersed, despite their significantly improved cross-national understandings and English competencies. Their level of intention to mobilize the US education system, in other words, did not necessarily increase with their better crossnational understanding.

\section{Acknowledgments}

None.

\section{Funding Information}

This work was funded by the Education Ministry of KSA, as per its Building Leadership for Change through School Immersion Program.

\section{Competing Interests}

The authors have no competing interests to declare. 


\section{Author Biographies}

Byoung-gyu Gong, Ph.D., is a data scientist at the Sorenson Impact Center in the David Eccles School of Business at University of Utah in Salt Lake City, Utah, United States. His research interests focus on the intersection of educational policy and data analytics. He uses computational social science methods such as text mining, network analysis, and predictive modeling to gain new educational policy insights and to map out educational terrains across the countries and states.

Clarin Collins, Ph.D., is the director of scholarly initiatives in the Mary Lou Fulton Teachers College at Arizona State University, Tempe, Arizona, United States. Her research interests include national and state policy implementations at the local level, teacher interactions with and influences on educational policy, and educational accountability and evaluation systems.

Audrey Amrein-Beardsley, Ph.D., is a professor in the Mary Lou Fulton Teachers College at Arizona State University, Tempe, Arizona, United States. She specializes in tests and assessments, validity and reliability, survey research, and research and program evaluation methods. She also researches the uses of value-added models (VAMs) for the evaluation of teacher and school effects on student learning and achievement.

\section{References}

[1] Anderson-Levitt, K. M. (Ed.) (2003). Local meanings, global schooling: Anthropology and world culture theory. New York, NY: Palgrave Macmillan.

[2] Ashton, P., \& Webb, R. (1986). Making a difference: Teachers' sense of efficacy and student achievement. New York, NY: Longman.

[3] Bandura, A. (1982). Self-efficacy mechanism in human Agency. American Psychologist, 37(2), 122-147. http://doi.org/10.1037/0003-066X.37.2.122

[4] Bandura, A. (1977). Self-efficacy: Toward a unifying theory of behavioral change. Psychological Review, 84(2), 191-215.

[5] Bandura, A. (2005). Guide for constructing self-efficacy scales. Self-efficacy Beliefs of Adolescents, 5(1), 307-337.

[6] Brindley, R., Quinn, S., \& Lou Morton, M. (2009). Consonance and dissonance in a study abroad program as a catalyst for professional development of pre-service teachers. Teaching and Teacher Education, 25(3), 525-532. http://doi.org/10.1016/j.tate.2008.09.012 
[7] Canfield, B. S., Low, L., \& Hovestadt, A. (2009). Cultural immersion as a learning method for expanding intercultural competencies. The Family Journal, 17(4), 318322.

[8] Cantrell, S. C., \& Hughes, H. K. (2008). Teacher efficacy and content literacy implementation: An exploration of the effects of extended professional development with coaching. Journal of Literacy Research, 40(1), 95-127. http://doi.org/10.1080/10862960802070442

[9] Cohen, J. (1988). Statistical power analysis for the behavioral sciences. New York, NY: Routledge Academic.

[10] Cohen, J. (1992). A power primer. Psychological Bulletin, 112(1), 155.

[11] Cook, M. (2010). Factors inhibiting and facilitating Japanese teachers of English in adopting communicative language teaching methodologies. K@ta, 11(2), 99-116.

[12] Cronbach, L. J. (1951). Coefficient alpha and the internal structure of tests. Psychometrika, 16(3), 297-334.

[13] Cushner, K. (2007). The role of experience in the making of internationally-minded teachers. Teacher Education Quarterly, Winter, 27-39.

[14] Dana, N. F., \& Yendol-Hoppey, D. (2015). The PLC book. Thousand Oaks, CA: Corwin Press.

[15] Darling-Hammond, L., \& Lieberman, A. (2012). Teacher education around the world: What can we learn from international practice? European Journal of Teacher Education, 4O(3), 291-309. http://doi.org/10.1080/02619768.2017.1315399

[16] Estimo Jr., R. C. (2015, November 6). 25,000 teachers to train abroad. Arab News. Retrieved from https://www.arabnews.com/saudi-arabia/news/831221

[17] Fitzpatrick, J. L., Sanders, J. R., \& Worthen, B. R. (2011). Program evaluation: Alternative approaches and practical guidelines. Boston: Pearson.

[18] Freeman, R. (1993, 2009). Collaboration, global perspectives, and teacher education. Theory into Practice, 32(1), 33-39. http://doi.org/10.1080/00405849309543570

[19] Gibson, S., \& Dembo, M. H. (1984). Teacher efficacy: A construct validation. Journal of Educational Psychology, 76(4), 569-582.

[20] Glaser, B. (1987). Theoretical sensitivity. Mill Valley, CA: Sociology Press.

[21] Gleeson, M., \& Tait, C. (2012). Teachers as sojourners: Transitory communities in short study-abroad programmes. Teaching and Teacher Education, 28(8), 1144-1151. http://doi.org/10.1016/j.tate.2012.07.005 
[22] Kabilan, M. K. (2013). A phenomenological study of an international teaching practicum: Pre-service teachers' experiences of professional development. Teaching and Teacher Education, 36, 198-209. http://doi.org/10.1016/j.tate.2013.07.013

[23] Kaszuba, A. (2018). A comparison of teacher experiences between course-based and immersion-based FSL teacher education programs [Paper presentation]. The Graduate Student Research Conference, Toronto, Canada.

[24] Kingdom of Saudia Arabia (KSA). (n.d.). Vision 2030. Retrieved from https://www.vision2030.gov.sa/

[25] Kitchen, J., Berry, M., \& Russell, T. (2019) The power of collaboration. Studying Teacher Education, 15(2), 93-97. http://doi.org/10.1080/17425964.2019.1628560

[26] Klassen, R. M., Tze, V. M. C., Betts, S. M., \& Gordon, K. A. (2011). Teacher efficacy research 1998-2009: Signs of progress or unfulfilled promise? Educational Psychology Review, 23, 21-43.

[27] Lee, J. F. K. (2011). International field experience - What do student teachers learn? Australian Journal of Teacher Education, 36(10), 1-23. http://doi.org/10.14221/ajte.2011v36n10.4

[28] Lunenberg, M., Murray, J., Smith, K., \& Vanderlinde, R. (2017). Collaborative teacher educator professional development in Europe: Different voices, one goal. Professional Development in Education, 43(4), 556-572. http://doi.org/10.1080/19415257.2016.1206032

[29] Mahler, D., Großschedl, J., \& Harms, U. (2018). Does motivation matter? - The relationship between teachers' self-efficacy and enthusiasm and students' performance. PLOS ONE, 13(11), e0207252-18. http://doi.org/10.1371/journal.pone.0207252

[30] McCoach, D. B., \& Colbert, R. D. (2017). Factors underlying the collective teacher efficacy scale and their mediating role in the effect of socioeconomic status on academic achievement at the school level. Measurement and Evaluation in Counseling and Development, 43(1), 31-47. http://doi.org/10.1177/0748175610362368

[31] Merriam, S. B., \& Tisdell, E. J. (2016). Qualitative research: A guide to design and implementation. San Francisco: Jossey-Bass.

[32] Nir, A., Kondakci, Y., \& Emil, S. (2017). Travelling policies and contextual considerations: on threshold criteria. Compare: A Journal of Comparative and International Education, 48(1), 1-18. http://doi.org/10.1080/03057925.2017.1281102

[33] Nulty, D. D. (2008). The adequacy of response rates to online and paper surveys: What can be done? Assessment \& Evaluation in Higher Education, 33(3), 301-314. http://doi.org/10.1080/0260293070129323

[34] Nunnally, J. C. (1978). Psychometric theory (2 ${ }^{\text {nd }}$ ed.). New York, NY: McGraw-Hill. 
[35] Okken, G. J., Jansen, E. P. W. A., Hofman, W. H. A., \& Coelen, R. J. (2019). Beyond the 'welcome-back party': The enriched repertoire of professional teacher behaviour as a result of study abroad. Teaching and Teacher Education, 86, 102927. http://doi.org/10.1016/j.tate.2019.102927

[36] Organisation for Economic Co-operation and Development (OECD). (2019). PISA 2018 results (Volume l): What students know and can Do. Paris: PISA, OECD Publishing. https://doi.org/10.1787/5f07c754-en

[37] Pence, H. M., \& Macgillivray, I. K. (2008). The impact of an international field experience on preservice teachers. Teaching and Teacher Education, 24(1), 14-25. http://doi.org/10.1016/j.tate.2007.01.003

[38] Phillips, D. (2006). Toward a theory of policy attraction in education. In G. SteinerKhamsi (Ed.), The global politics of educational borrowing and lending. New York, NY: Teachers College Press, Columbia University.

[39] Postareff, L., Lindblom-Ylänne, S., \& Nevgi, A. (2007). The effect of pedagogical training on teaching in higher education. Teaching and Teacher Education, 23(5), 557-571. http://doi.org/10.1016/j.tate.2006.11.013

[40] Rodriguez, E. (2012). What pre-service teachers bring home when they travel abroad. Scholar-Practitioner Quarterly, 5(3), 289-305.

[41] Sharma, S., Phillion, J., \& Malewski, E. (2011). Examining the practice of critical reflection for developing pre-service teachers' multicultural competencies: Findings from a study abroad program in Honduras. Issues in Teacher Education, 20(2), 9-22.

[42] Skaalvik, E. M., \& Skaalvik, S. (2007). Dimensions of teacher self-efficacy and relations with strain factors, perceived collective teacher efficacy, and teacher burnout. Journal of Educational Psychology, 99(3), 611-625. http://doi.org/10.1037/00220663.99.3.611

[43] Song, J., Sharma, U., \& Choi, H. (2019). Impact of teacher education on preservice regular school teachers' attitudes, intentions, concerns and self-efficacy about inclusive education in South Korea. Teaching and Teacher Education, 86, 102901. http://doi.org/10.1016/j.tate.2019.102901

[44] Snow-Gerono, J. L. (2005). Professional development in a culture of inquiry: PDS teachers identify the benefits of professional learning communities. Teaching and Teacher Education, 21(3), 241-256. http://doi.org/10.1016/j.tate.2004.06.008

[45] Stake, R. E., \& Trumbull, D. (1982). Naturalistic generalizations. Review Journal of Philosophy and Social Science, 7(1-2), 1-12.

[46] Steiner-Khamsi, G., \& Waldow, F. (Eds.) (2012). Policy borrowing and lending in education. New York: Routledge. 
[47] Tan, C. (2016). Tensions and challenges in China's education policy borrowing. Educational Research, 58(2), 1-12. http://doi.org/10.1080/00131881.2016.1165551

[48] Tavakol, M., \& Dennick, R. (2011). Making sense of Cronbach's alpha. International Journal of Medical Education, 2, 53-55.

[49] Tillema, H. H. (2000). Belief change towards self-directed learning in student teachers: Immersion in practice or reflection on action. Teaching and Teacher Education, 16(5-6), 575-591.

[50] Todeva, E., \& Knoke, D. (2005). Strategic alliances and models of collaboration. International Management, Strategy and Enterprise Research, 43(1), 123-148. http://doi.org/10.1108/00251740510572533

[51] Tomlinson-Clarke, S. M., \& Clarke, D. (2010). Culturally focused communitycentered service learning: An international cultural immersion experience. Journal of Multicultural Counseling and Development, 38(3), 166-175.

[52] Tschannen-Moran, M., \& Hoy, A. W. (2001). Teacher efficacy: Capturing an elusive construct. Teaching and Teacher Education, 17(7), 783-805. http://doi.org/10.1016/S0742-051X(01)00036-1

[53] Tschannen-Moran, M., \& McMaster, P. (2009). Sources of self-efficacy: Four professional development formats and their relationship to self-efficacy and implementation of a new teaching strategy. The Elementary School Journal, 110(2), 228-245. http://doi.org/10.1086/605771

[54] Yeo, S. S., \& Yoo, S.-S. (2019). Cultural disequilibrium: Struggles and strategies in intercultural settings in the case of exchange teachers invited to Korea. 